É possível aplicar a psicanálise à educação nos termos de uma profilaxia das neuroses do ato civilizacional? Nos textos de Freud, essa questão oscila entre o necessário e o contingente, próprio das condiçōes políticas, sociais e religiosas de sua época.

Psicanálise e educação; civilização; educação de crianças

SIGMUND FREUD, THE EDUCATION AND THE CHILDREN

Is it possible to apply psychoanalisis to education in terms of neurosis prophylaxis and civilization action? In the works of Freud, this question hesitates between the necessary and contingent, constitued by political, social and religious conditions of this time. Psychoanalisis and education; civilization; education of children

\section{SIGMUND FREUD, A EDUCAÇÃO E AS CRIANÇAS ${ }^{1}$}

Em não poucas oportunidades, Freud exprimiu sua pretensão de que a psicanálise não viesse a ficar restrita ao âmbito da "cura de certas formas da nervosidade" (1913a, p. 1851). Em 1913, afirmou em Scientia que a psicanálise reveste um múltiplo interesse. Já em 1932, lembrou o auditório imaginário da Lección XXXIV da pertinência das "aplicaçōes não médicas da psicanálise” (1932a, p. 3184). Porém, não se limitou a colocar o acento na possibilidade de expandir a teoria para além das fronteiras estritas da clínica. De fato, deteve-se também a justificar expressamente o manuseio da própria psicanálise por parte de profanos, como em 1926, por ocasião do affaire Reik ${ }^{2}$. Obviamente, depois de um século de psicanálise, nem a impugnação do monopólio médico no exercício clínico nem o múltiplo interesse da teoria analítica "para as ciências não psicológicas" são objeto de surpresa (Freud, 1913a, p. 1847). Entretanto, a questão da incidência da psicanálise além das suas fronteiras disciplinares hoje consagradas volta ao centro do debate quando se lembra que, nessas mesmas oportunidades, Freud fez referência ora à "aplicação da psicanálise à pedagogia", ora ao exercício de "analíticos pedagogos ou pedagogos analíticos". 


\section{Artigo}

O que se começou a chamar nos últimos tempos, e em alguns países, de conexão psicanálise-educação, cuja origem remonta às referências que o próprio Freud fez à educação infantil e ao ideário pedagógico de sua época, dista de ser um campo de grandes acordos. Talvez não pudesse ser de outra forma, considerando-se não só que - como o próprio Freud o confessara em várias passagens de sua obra - o seu "aporte pessoal a esta aplicação da psicanálise" foi de fato escasso, mas também porque é em torno das crianças que gravitam todas as ilusões adultas sobre um "mundo melhor" (1925, p. 3216). Além do fato de Freud não ter sido explícito o suficiente, poder-se-ia também pensar que essa falta de consenso revela que, precisamente, neste contexto de suposta "aplicação" revela-se implicada uma incidência possível da psicanálise no social e no político ${ }^{3}$. Assim, não teríamos muito do que estranhar, pois o debate acerca dessa incidência recobre, por sua vez, aquele outro em torno dos limites da própria psicanálise.

Mais ainda, caberia também afirmar que o fato de os adultos perderem a clareza espiritual quando tanto se fala de crianças como dos tempos futuros pode alertar no sentido de não nos espantarmos com os próprios ziguezagues freudianos em matéria da "aplicação da psicanálise à pedagogia". Como se sabe, Freud festejou os empreendimentos de sua filha Anna, bem como não deixou de esperar que esta "aplicação não médica" viesse a garantir um futuro não só para essa, mas também a sua outra estimada criatura - a psicanálise ${ }^{4}$.

Nos primeiros tempos desta "aplicação" - que se chamou de pedagogia psicanalítica ${ }^{5}$ os empreendimentos e adeptos não foram, como sabemos, poucos. Entretanto, em contraposição ao entusiasmo pouco cuidadoso dos pioneiros, hoje em dia já contamos com um pouco mais de duas décadas de ceticismo e cuidado reflexivo. De fato, a elucidação da impossibilidade de uma pedagogia analítica, empreendida dentre outros por C. Millot, JC. Bigeault e G. Terrier ${ }^{6}$, acertou as contas com a ilusão psicanalítica na educação.

Porém, a impugnação criteriosa da suposta pertinência de uma educação justificada psicanaliticamente - fruto da superposição dos lugares do analista e do educador e, portanto, dotada de suposta potestade profilática em matéria psíquica - incorreu, por sua vez, num pequeno descuido quando, sem mais, sentenciou, por um lado, que as referências freudianas ao assunto devem ser consideradas como meras "exortações à mesura" (Millot, 1979, p. 204) e, por outro, que "a incidência da psicanálise na civilização moderna não passa em modo algum por uma reforma educativa" (p. 157). Ao nosso ver, embora ambas afirmações sejam em certo sentido verda- 
deiras, as incursões de Freud na Pedagogia reclamam um outro exame na espera de se poder recolocar sob outro ângulo a pergunta pela possibilidade da incidência da psicanálise no social e no político, ao menos quando se trata de crianças.

Dessa forma, embora também seja verdade, conforme aponta $\mathrm{Mi}$ llot, que "o único auxílio que a psicanálise parece capaz de apontar à educação (..). seja de caráter (...) analítico", talvez se possa pensar que esse "auxílio analítico" não se reduz à proposta de cura analítica em massa para crianças e educadores.

O termo pedagogia psicanalítica não recobre o conjunto das incursões psicanalíticas na educação. Entende-se por tal a pretensão de se encontrar uma educação "no ponto", ou seja, uma matriz de intervenções junto às crianças capaz de vir a convertê-las em adultos sem padecimentos psíquicos. Essa nova pedagogia, resultante da conjugação de um pouco de educação e um outro tanto de psicanálise teria, então, poderes profiláticos. Em suma, quando se pensa em termos de pedagogia psicanalítica, almeja-se encontrar a fórmula do balanceio para crianças do processo civilizacional.

Hoje em dia, não há, ao menos no campo psicanalítico, nenhuma pretensão nesse sentido. Entretanto, sabemos que não foi sempre assim. Basta lembrar o pioneirismo de Anna Freud, dentre muitos outros empreendedores no mundo da psicoprofilaxia para crianças, em particular.

Toda pretensão de se prevenirem as neuroses e as perversões gra- 
ças a uma suposta educação adequada está alicerçada numa leitura dos textos freudianos que desconhece a estrutura paradoxal do desejo revelada pela experiência psicanalítica. Essa "leitura parcial" de Freud pode ser creditada na conta do tempo, ou seja, no tempo que foi necessário para o advento lacaniano de um "retorno a Freud". Mas também cabe lembrar que a pretensão psicoprofilática, que se reivindicou freudiana, esqueceu simplesmente de ler a advertência da sua impossibilidade estrutural que o próprio Freud formulara, com clareza e distinção, em Análisis terminable e interminable (1937). Em suma, mesmo tendo the sido possível brandir a seu favor La ilustración sexual del niño (1907) y La moral sexual "cultural" y la nerviosidad moderna (1908), não poderia não ter avançado mais um pouco na leitura ao menos cronológica.

Entretanto, o fato de não haver dúvidas sobre a impertinência da psicoprofilaxia não implica, necessariamente, a existência de um "primeiro" e "segundo Freud" em matéria educativa como, dentre outros, sustentara C. Millot. Em outras palavras, a desilusão do próprio Freud com relação à psicoprofilaxia não arrasta consigo sua esperança de que a "aplicação da psicanálise (...) à educação das gerações vindouras” (1932a, p. 3184) venha a alterar o status quo pedagógico, responsável pelo cumprimento imperfeito da sua devida missão (p. 3186).

A esperança de uma outra educação é uma constante nos textos freudianos. De fato, ela está, até certo ponto, colada à ilusão profilática como, por exemplo, nos textos de 1907, 1908, no Prefacio para un libro de Oskar Pfister (1913), na Lección XXIII (1915-17) e em Análisis profano (1926), mas a separação processa-se ao longo da obra. Já em 1909, por ocasião de Análisis de la fobia de un niño de cinco años, ao mesmo tempo em que reconhece ser no mínimo problemática a questão da profilaxia, mantém a aposta na troca dos fins educativos ${ }^{7}$. Logo, na Lección XXXIV - considerada classicamente como o enterro de toda esperança - Freud observa mais uma vez a dificuldade de se levar à prática a profilaxia junto às crianças, ao mesmo tempo em que esboça a análise dos educadores como uma possibilidade sui generis para que a educação venha a encontrar seu caminho.

Os remanejamentos do modelo pulsional, que culminaram no postulado da irredutibilidade antinômica entre as pulsões de vida e de morte, foram corroendo a ilusão profilática, quando possibilitavam o reconhecimento de que "o plano da Criação não inclui o propósito de que o homem seja feliz” (Freud, 1929, p. 3025), até o abandono explícito da mesma no texto de 1937. Porém, Freud manteve firme sua esperança a qual batizou, finalmente, de “educação para a realidade” (1927, p. 2988). Essa, diferentemente 
daquela proposta na sua época - em particular, pela "piedade cristã" (1932b, p. 3205) à moda do idealismo germânico ou da cultura norte-americana ${ }^{8}$, mas também pelo bolchevismo russo ${ }^{9}$-, deveria evitar a "miséria psicológica das massas"(1929, p. 3049), apesar de não poder mudar "notadamente a essência psicológica do homem" (1927, p. 2991). Em suma, a esperança freudiana manteve-se constante na medida em que não se articula como mais uma reforma educativa em sentido estrito, ou seja, em prol de um fim profilático desejado.

Por outro lado, cabe observar que ao longo dos textos freudianos também se processa, de forma cruzada à anterior e não menos tensa, uma outra distinção importante: aquela que medeia entre a psicanálise com crianças e a educação infantil resultante da dita aplicação da psicanálise. No início, a primeira empresa se anuncia através da segunda e ambas se confundem nas mãos de Pfister e de Anna. Porém, ambas deixam de se recobrir totalmente, embora Freud continue a manter uma certa oscilação, talvez devida ao fato de sua filha estar, precisamente, no meio deste affaire.

Dessa forma, primeiramente encontramos, sem lugar a dúvidas, que ao processo educativo de uma criança pode se lhe acrescentar, com fins profiláticos, um pouco de psicanálise como, por exemplo, em Multiple interés del psiconálisis, Prefacio para un libro de Pfister e em Análisis profano. Freud refere-se ao resultado dessa conjunção em termos de "tratamento misto" e "análise de crianças". Assim, a psicanálise enxerta-se na educação e produz como novidade um tratamento psicoprofilático que, por sua vez, reforça a defesa freudiana do exercício profano da psicanálise ${ }^{10}$.

Entretanto, em segundo lugar, em Prefacio para un libro de A. Airchhorn (1925), Freud declara, por um lado, que a tarefa pedagógica é algo sui generis que não pode ser confundida nem substituída pela influência psicanalítica e, por outro, a "psicanálise de crianças" pode intervir como "um recurso auxiliar" quando assim for necessário. Mais ainda, apesar de a psicanálise do adulto neurótico ser equivalente a uma reeducação, frisa que a educação das crianças reclama "outra coisa diferente da análise mesmo que coincida com ela no objetivo". Esta "outra coisa” só pode ser uma outra educação que não a proposta pela pedagogia da época. Ela, em virtude de ser o resultado da "aplicação" de uma sobre a outra, passaria a compartilhar o objetivo da "situação analítica" que pelo fato de exigir "o desenvolvimento de determinadas estruturas psíquicas e uma atitude singular perante o analista” não pode ser aplicada a um "ser imaturo". Essas "condições particulares" faltam também no "jovem abandonado" - campo de intervenção de Aichhorn - e no "criminal impulsivo". Aquilo que falta - sinal de uma 
espécie de imaturidade que reclama à educação - é condição da operatividade da situação analítica que, em se tratando de adultos, equivale a uma reeducação. Em suma, lembrando que o objetivo de uma análise é, em termos freudianos, levar o adulto neurótico a reconhecer aquilo de que se defende sintomaticamente - a lei do desejo - devido a um inevitável defeito educativo, podemos concluir que a imaturidade infantil reclama por uma intervenção que, à diferença da pedagogia da época, enverede a criança rumo à castração que humaniza.

Finalmente, na Lección $X X X I V$, Freud manifesta rapidamente sua satisfação pelo fato de sua filha estar empenhada naquilo que ele considera tanto importante quanto promissor. Porém, logo mais, detém-se a examinar a "missão primeira da educação", declara que até esse momento a educação cumpriu imperfeitamente sua missão, bem como a "educação psicanalítica” visa fazer da criança um "homem sadio e eficiente", que não venha a se colocar "ao lado dos inimigos do progresso". Em suma, Freud acaba recuperando a distinção, apresentada em 1925, entre a psicanálise com crianças e uma esperada educação, capaz de submeter as crianças à castração que de outra forma bem poderia vir a não operar psiquicamente.

Dessa forma, temos que a psicoprofilaxia ou garantia antecipada de bem-estar é, de fato, abandonada; a nascente psicanálise com crianças revela-se incapaz de substituir a educação primordial, bem como esta última, ao reclamar o auxílio analítico, uma vez que a pedagogia atrapalha mais do que ajuda, isto ocupa o foco das preocupações de um Freud sempre "fascinado" pelos "problemas culturais" - como diria de si mesmo em Autobiografia (1924).

$$
x+2
$$

A crítica freudiana à pedagogia da época começou a ser esboçada em Tres ensayos para una teoria sexual (1905) quando da avaliação do estatuto da educação na produção dos "diques anímicos que se opõem ao instinto sexual". Logo, em Ilustración sexual del niño, Freud a considerou expressamente perniciosa do ponto de vista psíquico, uma vez que se fundamenta no "engano no terreno sexual e na intimidação no terreno religioso”. Já em La moral sexual cultural y la nerviosidad moderna, volta à crítica da educação, pois ela veicula desde a infância a "moral sexual cultural" em causa na "nervosidade moderna" que atinge os adultos.

Dessa forma, parece que, se a crítica visa ao caráter excessivo da moral adulta em voga e veiculada já na infância pela educação, então Freud pressupõe que o mal-estar na civilização é contingente, a total satisfação pulsional é possível, bem como urge uma reforma educativa com fins profiláticos à luz da psicanálise. Mais ainda, se assim fosse, teríamos um "primeiro Freud" que a promoção da pulsão de morte na teoria analítica teria se encarregado de soterrar, apesar do desconhecimento dos partidários da pedagogia psicanalítica. Porém, parece-nos, por um lado, que tanto esses últimos quanto seus justos detratores supõem que o problema em pauta na época 
seria quantitativo e, por outro, que, embora o próprio Freud tenha feito várias referências à possibilidade $\mathrm{da}$ psicoprofilaxia, já há elementos nos textos, anteriores a 1920 , que tanto invalidariam a ilusão da harmonia quanto permitiriam ler, ao contrário, numa chave qualitativa a crítica à pedagogia da época.

$\mathrm{Na}$ contramaré das aparências de um "primeiro Freud", encontramos uma reflexão sobre a irredutibilidade estrutural do desprazer psíquico e, portanto, da impertinência de pretender encontrar uma dosagem melhor das restrições civilizadoras.

Já antes de 1900, no Manuscrit $K$, endereçado a Fliess em 01/01/ 1896, Freud, reexaminando o estatuto da relação entre pudor, moralidade, recalcamento e desprazer, afirma que "deve haver na sexualidade uma fonte independente de desprazer; se essa fonte existir, ela pode alimentar as sensações de nojo e dar força à moralidade" (1987-1902, p. 131). Na carta datada de 14/11/1897, afirma que a moral, ao contrário do que poderia se pensar, resulta do recalcamento que, por sua vez, possui "um elemento orgânico" - "abandono das antigas zonas sexuais" devido à conquista da posição ereta do homem (p. 205). A irredutibilidade do desprazer psíquico é também referida no Projeto de una psicologia para neurólogos (1895). A organização psíquica é pensada em termos de uma "adquisição biológica" de "barreiras" contra a "ameaça de desprazer", derivada da própria "tendência básica do sistema neurônico" "1. Assim, haveria uma "defesa normal" e um "recalque histérico" perante uma invariável 
ameaça de desprazer. Por outro lado, Freud alude ao caráter restritivo inevitável da civilização, quando afirma, no Manuscrit $N$, em 31/05/1897: "o incesto é um fato anti-social ao qual a sociedade deveu aos poucos renunciar para poder existir" (p. 186).

Logo após a virada do século, Freud se refere, em Tres ensayos, à existência de impulsos em si mesmos perversos que podendo acarretar só desprazer reclamam pela "ação de forças psíquicas contrárias". Em 1912, em Sobre una degradación general de la vida erótica, declara que o resto de insatisfação, inerente à "natureza mesma do instinto sexual", é "fonte de máximos rendimentos culturais" quando "submetido às primeiras normas da civilização". E, finalmente, em El malestar en la cultura (1929), Freud afirma, já sem rodeios, que o desprazer é o efeito inevitável da humanização, devido à tensão contraditória inerente à bissexualidade constitutiva, ao fato da relação erótica comportar também "tendências agressivas diretas", bem como, fundamentalmente, à "adoção da postura bípede e à desvalorização das sensações olfativas”.

Dessa forma, em se tratando de uma impossibilidade estrutural de haver uma satisfação total e prazerosa, Freud não se ilude nunca com uma educação "no ponto" capaz de não implicar desprazer psíquico. Mais ainda, se houvesse a possibilidade de encontrar a quantidade certa de satisfação/restrição, daí não reservaria à educação um papel modesto na modificação do quadro de base.

Desde o início, consta o reconhecimento de uma eficácia limitada à educação ou, em outras palavras, do fato de a margem de manobra dos adultos junto às crianças padecer de uma certa limitação intrínseca. Em Tres ensayos, após afirmar que os "diques" contra o "instinto sexual" são obra da educação, Freud declara que a evolução sexual encontra-se "organicamente condicionada e fixada pela herança e pode se produzir sem auxílio nenhum da educação" de forma tal que essa última se mantém "dentro de seus limites, restringindo-se a seguir as trilhas do organicamente préformado ". Pois bem, se lembrarmos que o apelo às teses da herança filogênica e da pré-formação orgânica ou adquisição biológica era o recurso disponível na época para se estabelecer na reflexão uma determinação estrutural, então Freud reconhece no adulto uma possibilidade limitada de vir a conjurar a desarmonia quantitativa implicada na evolução da criança.

Essa oposição necessário/contingente se reinscreve, em Múltiple interés del psicoanálisis, na forma espontâneo/exterior. $\mathrm{Na}$ oportunidade, afirma que a "repressão violenta dos instintos" "produzida do exterior" não equivale à "produção espontânea" de repressões por parte da própria criança que, assim, repete "uma parte da história da civilização", a qual "produzida do exterior" significa de 
forma extemporânea ou sem guardar as devidas proporções ${ }^{12}$ no interior de um processo de evolução psíquica determinado estruturalmente ${ }^{13}$, ou seja, em si mesmo "espontâneo", uma vez que não obedece ao livre-arbítrio dos partícipes.

Em suma, Freud, apesar de se iludir com a possibilidade da profilaxia, não cifra suas esperanças em um manejo quantitativo da intervenção educativa.

Nesse sentido, se lembrarmos que a crítica à educação da época é uma constante nos textos freudianos, ainda caberia analisar qual seria o objeto da mesma, ou seja, o estofo de sua criticada violência não-natural. Para tanto, pensamos ser necessário colocar o problema num viés qualitativo. Isto é, não se trataria de pressupor que Freud num primeiro momento iludiu-se com uma educação menos repressiva, mas sempre esperou por uma qualidade diferente de intervenção dos adultos junto às crianças ou seja, que os adultos pudessem vir a se endereçar às crianças em nome de outra coisa que a moral de seu tempo - batizada de "educação para a realidade".

Na mesma Lección $X X X I V$, Freud afirma, por oposição ao ideário pedagógico hegemônico no início deste século, que a educação deve "buscar seu caminho entre o laisser-faire e a frustração", bem como a "missão" da "educação psicanalítica"l4 consiste em fazer do educando um "homem sadio e eficiente" com vistas a não acabar se colocando "ao lado dos inimigos do progresso". Ou seja, estabelece uma diferença substancial entre o que deveria ser o fruto da, assim chamada por Freud, "aplicação da psicanálise" e a educação de sua época, implementada à luz de uma pedagogia de cunho religioso-moral. Nessa oportunidade, não faz mais do que recuperar a diferença já assinalada em "El porvenir de una ilusión" entre, por um lado, a natureza "irreligiosa" da "educação para a realidade", promovida pela psicanálise, e, por outro, o "programa pedagógico" da época, centrado na "demora da evolução sexual e a precocidade da influência religiosa", responsável pela coerção da atividade e curiosidade intelectuais ${ }^{15}$.

A educação para a realidade adquire sentido por oposição àquela promovida pela pedagogia religiosa das primeiras décadas do século XX. A realidade para Freud está longe de ser a dita realidade cotidiana e, portanto, o seu anseio não deve ser entendido num sentido psicológico-adaptacionista ${ }^{16}$. Por um lado, cabe lembrar que essa proposição educativa está sobreposta à definição da educação, em si mesma, como "o estímulo ao vencimento do princípio de prazer e a substituição do mesmo pelo princípio de realidade" (Freud, 1911, p. 1641) e, por outro, a realidade cotidi- 
ana, produto das ilusões religiosas, não é outra coisa que uma espécie de grande "neurose coletiva" - objeto de um futuro estudo sobre a "patologia das comunidades culturais" (1929, p. 3067).

Assim sendo, educar para a realidade é sinônimo de educar para o desejo ou, se preferirmos, de educar com vistas a possibilitar o reconhecimento da impossivel realidade do desejo - ou seja, o caráter artificialista de seu estofo -, aquela que, precisamente, as ilusões religiosas mascaram.

Em contrapartida, é possível apurar o teor da crítica à moral religiosa no contexto da análise freudiana acerca da impertinência de considerar a teoria psicanalítica uma Weltanschauung particular. Freud afirma que "a religião...explica (aos homens) a origem e gênese do Universo, assegura-lhes proteção e gozo final nas vicissitudes da vida e orienta suas opiniões, bem como seus atos com prescrições que sustenta com toda sua autoridade. Cumpre, assim, três funções: (...) satisfaz a vontade de saber dos homens (...); mitiga o medo dos homens perante os perigos e as vicissitudes da vida (...); formula prescrições, proibições e restrições" (1932b, p. 3193). Continuando, sustenta que "As exigências éticas, às quais a religião quer dar sustentação, demandam, pelo contrário, um fundamento diferente, pois são indispensáveis à sociedade humana" (p. 3197).

Em suma, a crítica à religião não parece ser o reverso de uma ingênua esperança libertária, embora seja, como o próprio Freud confessara ao pastor Pfister, um produto 
de sua condição de "herético e ímpio" (1909-1939, p. 162). A religião parece focalizar de fato seu cunho justificacionista, isto é, obturadora da mesmíssima dimensão ética do agir humano. Freud, por um lado, parece estar persuadido de que, na medida em que o homem obedece em nome de algum Deus ${ }^{17}$, sua ação encontra justificativa em uma realidade espiritual transcendente à vida social, bem como ganha uma certeza subjetiva. Assim, quando de suas mãos escorrega toda ilusão divina, torna-se possível formular a pergunta sobre o desejo que anima seu ato e, por conseguinte, venha a se perfilar no horizonte uma nuvem de incerteza espiritual ou inquietação moral. Entretanto, Freud assinala não só a necessidade em si das exigências morais mas também de vir a lhes outorgar um outro "fundamento" ${ }^{18}$. De fato, acredita-se possível considerar a empreitada freudiana de substituir os motivos religiosos da moral por outros puramente terrenos, como uma crítica a todo essencialismo ético, tendente sempre a recusar, como lembrara Lacan no Seminário VII, o caráter ex nihilo das criações discursivas morais ou, se preferirmos, a fragilidade inerente à existência artificialista do homem.

Nesse sentido, a "moral sexual cultural" dos adultos, considerada "hipócrita", pois impede o homem de "viver com regularidade sua verdade psicológica” (Freud, 1915, p. 2107), apõe-se no início da reflexão freudiana à moral "natural". Isto é, na "moral sexual cultural", o homem não pode se reconhecer enquanto dividido e desejante. Mais ainda, a pedagogia da época produz "conflito psíquico" (1908, p. 1264) ou "recalque violento" (1913a, p. 1866) uma vez que, ocultando sistematicamente o sexual e intimidando no terreno religioso, torna a tramitação das pulsões infantis um fato de difícil acontecimento, e não, como muitos autores pensaram, porque ela exagerasse na quantidade de restrições comportamentais.

Embora cientes do caráter rico em nuanças, bem como espinhoso, do debate religião-psicanálise e/ou ciência, consideramos ser possível observar que Freud não chega em momento algum a sustentar em nome da psicanálise a inverdade das doutrinas religiosas, embora, é claro, o tenha feito em nome próprio. Apenas, na medida em que indaga a significação psicológica das mesmas, conclui que se trata de ilusões, isto é, crenças não necessariamente erradas nem improváveis de responderem aos cânones da razão científica da época.

Nesse sentido, poder-se-ia afirmar que pretendia elucidar um aspecto em especial das doutrinas religiosas que, hoje, bem poderia ser chamado de fundamentalismo religioso. Assim, caberia a possibilidade de se demarcar uma diferença sutil entre religiosidade e fundamentalismo, isto é, uma crença fora de medida ou de toda razão. 
Em suma, seria psiquicamente possivel acreditar em doutrinas religiosas sem cair nas garras do fundamentalismo religioso ou no impasse próprio de um justificacionismo ético, seja ele religioso ou não. Como reza a letra de uma música popular latino-americana - "solo le pido a Dios que el futuro no me sea indiferente" (L. Gieco) -, o sujeito bem pode apenas pedir a Deus que não the tire sua própria responsabilidade pelo futuro, a possibilidade de se empenhar existencialmente num ato ou de vir a agir em nome do desejo ${ }^{19}$. Mas também seria psiquicamente possível brandir um certo ateísmo e, entretanto, estar espiritualmente tomado num ilusionismo fundamentalista como, por exemplo, no caso do bolchevismo russo. Bem como, finalmente, um sujeito irreligioso no caso Sigmund Freud - bem pode ter a esperança de que o futuro da humanidade seja desprovido de ilusões religiosas, ou não, apesar de estar ciente da dificuldade de que tal coisa venha a acontecer ${ }^{20}$.

Nesse contexto, parece que a persistente crítica freudiana à educação da época não só não é a expressão de nenhuma espécie de cinismo socioeducativo, como aponta para o aspecto central do ideário educativo hegemônico nas primeiras décadas - seu justificacionismo pedagógico, epifenômeno do fundamentalismo cultural que tomava conta da cultura, em particular no mundo germânico, nos EUA e na Rússia.

A educação para a realidade, que Freud "iludiu", poderia ser pensada como uma educação além do justificacionismo pedagógico de cunho moral-religioso hegemônico na sua época. É provável que essa idéia tenha acompanhado Freud durante anos, pois consta ter afirmado, já em 1907: "A substituição do catecismo por um tratado elementar dos direitos e deveres do cidadão, como a implementada pelo Estado francês, parece-me um grande progresso na educação infantil" (Freud, 1907, p. 1248).

Dessa forma, Freud estaria esperando apenas que o futuro nos reserve uma "educação libertada das doutrinas religiosas" mesmo se ela não for capaz de mudar "notadamente a essência psicológica do homem" (1927, p. 2991), isto é, de produzir a harmonia psíquica que faz falta. Mais ainda, Freud considerava que, apesar de ser improvável que sua esperança viesse algum dia a se concretizar, "valia a pena tentar" (1927, p. 2987).

Nesse contexto, caberia afirmar que a crítica freudiana à pedagogia da época, imbuída de certo fundamentalismo religioso ou não, pressupunha a possibilidade de uma educação à seca. Freud estaria criticando a pedagogia fundamentalista enquanto apostava numa humilde educação sem fundamento transcendental algum e, portanto, na possibilidade de que o homem já adulto viesse a ex- 
perimentar algo como "o mundo não é uma nursery" (Freud, 1932 b, p. 3197) ou, se preferirmos, que o homem uma vez adulto suportasse a vida preparando-se para a morte ${ }^{21}$. Em outras palavras, mesmo que seja inevitável a vida se sustentar em ilusões, nada impede que o homem saiba inconscientemente que elas são isso mesmo, ou seja, a marca do desamparo existencial e não indícios de nenhuma transcendência. Assim, quando uma ilusão se sabe ilusão fica resguardada a distância entre o sujeito e o registro dos ideais, que não é outra que a fenda mesma do desejo.

$x * * 6$

Entretanto, independentemente de que semelhantes suposições possam dar lugar a uma questionável "psicologia do autor", cabe observar que estamos persuadidos de que na letra freudiana opera em filigrana uma diferença entre educação e pedagogia. Isto é, entre, por um lado, os efeitos subjetivantes ou formativos derivados para a criança de sua relação com os adultos e, por outro, o conjunto dos saberes positivos sobre uma suposta adequação entre os meios e os fins da educação. Mais ainda, pensamos que essa disjunção educação-pedagogia é capaz de elucidar também os impasses da educação de nossos dias.

A "educação" atual - em particular no império espiritual à moda ianque - está impregnada, à diferença de outrora, de certo fundamentalismo psiconaturalista. A educação nos dias de hoje é pensada como o processo de estimulação metódica e científica de uma série sem fim de capacidades psicomaturacionas. Assim reduzida, por um lado, a criança fica como objeto de saberes psicológicos especializados e, por outro, as vicissitudes do ato de educar para o desenvolvimento de uma racionalidade didático-instrumental acabam tornando improcedente ao adulto manter aberta a interrogação sobre o impossivel em torno do qual se articula sua própria relação com a criança.

O fundamentalismo psiconatural que alimenta o ideário pedagógico atual é, na mesma linha dos ganhos religiosos, capaz de erradicar a vontade de saber, bem como de mitigar o medo dos adultos perante os perigos e as vicissitudes da vida - escolar ou não - junto às crianças, na medida em que formula prescrições, proibições e restrições sempre justificadas.

Porém, em um ponto, as ilusões psiconaturalistas de hoje ganham das religiosas do tempo de Freud no que diz respeito à educação: tornam o reconhecimento do desejo que anima o ato um fato de difícil acontecimento e, portanto, reduzem toda e qualquer instância ou práxis educativa a uma resignada prática psicopedagógica.

A insistência religiosa em dominar o desejo, como, aliás, toda empresa neurótica, não faz senão colocar, uma e outra vez, o sujei- 


\section{Artigo}

to em uma mesma encruzilhada, qual seja aquela do reconhecimento de sua impossível realidade. Mas, embora a religião não recuse a realidade do desejo, ela condena o sujeito à reiteração do fracasso do recalque. Entretanto, essa "neurose coletiva" que toma conta do mundo adulto alimenta, segundo Freud na Lección $X X$ $X I V$, o risco das crianças virem, num futuro, a se colocar do lado dos "inimigos do progresso". Além disso, a forclusão do desejo, implicada nas ilusões psicopedagógicas atuais, dá margem a que as crianças venham a adoecer de resignado cinismo.

Há, por definição, antinomia entre a natureza artificial do desejo e o justificacionismo moral, próprio de todas as ilusões pedagógicas. Mas, o fato de a pedagogia moderna estar imbuída de um justificacionismo naturalista, ou seja, da certeza de que haveria uma adequação natural entre a intervenção educativa e o suposto nível psicológico da criança, implica a forclusão do desejo. Como Lacan o assinalara no seu Seminário VII, trata-se da marca própria da espiritualidade cientificista atual, solidária com uma moral ao "serviço dos bens" e, portanto, antinômica a uma "ética do desejo".

Obviamente, tanto um quanto outro risco de fracasso educativo, ou seja, tornar-se um inimigo do progresso ou um cínico, relevam um problema político. Assim, neste ponto, a psicanálise encontra seu próprio limite e o dever que se acaba colocando é, simplesmente, aquele de agir no mesmo nível político do problema, conforme observara, de forma expressa, Maud Mannoni em 
Education impossible (1973). Por sinal, talvez, ela tenha, nesse ponto, sabido seguir Freud, apesar de ele ter deixado em aberto a questão por ocasião da Lección XXXIV. De fato, é factível que Freud tenha querido marcar uma precavida distância das posições de Reich, para assim proteger a sua criatura psicanalítica do nazismo ${ }^{22}$. Mas, por que não pensar, também, se, ao afirmar que "não é missão do analítico decidir entre os partidos em pugna" uma vez que, por um lado, "toda educação é parcial" e, por outro, a psicanálise não está norteada por um fim parcial, Freud estaria, aqui, assinalando um limite intransponível para a psicanálise? (Freud, 1932a, p. 3186/7). Se, porventura, assim fosse, então, chegados à beira do limite, seriamos obrigados a deixar de analisar.

Antes de chegarmos às fronteiras da psicanálise, cabe prestar um auxílio analítico. O cumprimento desse dever desloca sempre mais um pouco - limite da própria psicanálise, como Freud demonstrou com suas incursões além do terreno terapêutico. Em princípio, a expansão ao infinito converteria à psicanálise numa visão de mundo. Todavia, semelhante risco só existe na medida em que o analista venha a esquecer que, apesar de sua insistência, nem tudo é analisável neste, nosso único, mundo. Nesse sentido, ao menos temos que, com a "aplicação da psicanálise" à educação - consistente na tarefa de corroermos as ilusões (psico)pedagógicas no interior mesmo do campo educativo a fim de tentar sempre uma educação para a realidade impossível do desejo -, o analista depara-se com um limite já não mais deslizante. Semelhante situação reclama do analista um outro engajamento para dar sustentação a uma verdade construída paradoxalmente pela "aplicação" da própria psicanálise, bem como vivifica a teoria, uma vez que esta se confronta com o seu avesso.

A psicanálise espreita-se na fronteira com a educação e assim ganha après coup um limite, enquanto o analista perde tal condição, por ter acabado passando dos limites. Porém, uma vez livre do dever de analisar, pode tomar partido em nome próprio nas discussões educativas visando, como dizia Hanna Arendt ${ }^{23}$, colocar uma e outra vez o mundo no seu ponto justo e dessa forma inocular nas crianças o germe do movimento de tentar o impossível.

\section{REFERÊNCIAS BIBLIOGRÁFICAS}

Arendt, H. (1996). La crisis de la educación. In Entre el pasado y el futuro. Barcelona: Península.

Bigeault, J-P. et Terrier, G. (1978). L'illusion psychanalytique en éducation. Paris: PUF.

Cifali, M. (1982). Freud pédagogue? Paris: InterEditions.

Freud, S. (1887-1902). Lettres à Wilhem Fliess. In La naissance de la psychanalyse. Paris: PUF, 1956.

--_-_ (1909-1939). Correspondence avec le pasteur Pfister. Paris: Gallimard, 1991.

(1895). Proyecto de una psicología para neurólogos. In Obras Completas (Vol.1). Madrid: Biblioteca Nueva, 1973. 
(1905). Tres ensayos para una teoría sexual. In Obras Completas (Vol. 2). Madrid: Biblioteca Nueva, 1973.

(1907). La ilustración sexual del niño. In op. cit.

(1908). La moral sexual cultural y la nerviosidad moderna. In op.cit.

- (1909). Análisis de la fobia de un niño de cinco años (caso Juanito). In op. cit.

(1910). Psicoanálisis. Cinco conferencias pronunciadas en la Clarck University. In op. cit.

(1911). Los dos principios del funcionamiento mental. In op. cit.

(1912). Sobre una degradación general de la vida erótica. In op. cit.

(1912-1913). Tótem y tabú. In op. cit.

(1913a). Múltiple interés del psicoanálisis. In op. cit.

(1913b). Prefacio para un libro de Oskar Pfister. In op.cit .

- - (1915). Consideraciones de actualidad sobre la guerra y la muerte. In op. cit.

(1915-17a). Lecciones introductorias al psicoanálisis - Lección XXI. Desarrollo de la libido y organizaciones sexuales. In op. cit.

(1915-17b). Lecciones introdutórias al psicoanálisis - Lección XXIII. Via de formación de sintomas. In op. cit.

---- (1924). Autobiografia. In Obras Completas. (Vol. 3). Madrid: Biblioteca Nueva, 1973.

-- (1925). Prefacio para un libro de August Airchhron. In op. cit .

--_- (1926). Análisis profano (psicoanálisis y medicina). In op. cit.

- (1927). El porvenir de una ilusión. In op. cit.

(1929). El malestar en la cultura.

In op. cit.

(1932a). Nuevas lecciones introductorias - Lección XXXIV. Aclaraciones, aplicaciones y observaciones. In op. cit. - (1932b). Nuevas lecciones introductorias - Lección XXXV. El problema de la concepción del universo (weltanschauung). In op. cit.

- (1937). Análisis terminable e interminable. In op. cit.

Lacan, J. (1959-60). Le Séminaire. Livre VII: L'éthique de la psychanalyse. Paris: Éditons du Seuil, 1986.

Lajonquière, L. de (2000). Psicanálise, Modernidade e Fraternidade. In M. R. KehI (org.) Função Fraterna. Rio de Janeiro, RJ: Relume Dumara.

Mannoni, M. (1973). Education impossible. Paris: du Seuil.

Millot, C. (1979). Freud AntiPedagogo. Buenos Aires: Paidós, 1982.

NOTAS

1 Versão portuguesa, parcialmente modificada, do texto publicado em L'Infantile, no 1, pp. 31-48, Martin Media Èditions e Unité de Recherche Psychonèse et Psychopatologie de Paris XIII, 2001.

2 Defesa expressa do exercicio por parte de pedagogos, reiterada na Autobiografia (1924), bem como no Prefacio para un $l i$ bro de A. Aichhorn (1925).

3 Possivel implicância, vislumbrada por Freud em "Análisis de la fobia de un niño de cinco anos" (1909).

4 Em carta a Pfister de 09/01/1909, exprime "Esperamos que a chama que preservamos laboriosamente de sua extinção atiçando-a em nosso terreno, transformar-se-á no vosso num incêndio no qual nós possamos ir buscar uma brasa incandescente" (p.48). Já numa outra, em 02/05/1912, declara “ (..) eu estou tentado pela certeza de ganhar um novo circulo de leitores entre os pedagogos (...) Nossa força de expansāo no meio médico é infelizmente estreita; é importante que botemos um pé lá fora onde for possivel" (p. 96/6). Corres- 
pondence avec le pasteur Pfister, Paris, Gallimard, 1991. Vinte anos depois, na "Lección XXXIV", refere-se à "aplicação da psicanálise à pedagogia" como a "atividade capital da análise" (p. 3184).

5 Parece que o surgimento do termo está atrelado à aparição em 1926 - saudada com entusiasmo por Freud - de Zeitschrift für psychoanalytische Pädagogik, sob a responsabilidade editorial de Henrich Meng e Ernest Schneider. A publicação encerrou-se em 1937 devido ao avanço nazista.

6 Freud AntiPedagogo, Buenos Aires: Paidós, 1982; L'illusion psychnalytique en éducation, Paris: PUF, 1978.

7 Propóe trocar a "dominação (...) dos instintos" pela tarefa de tornar o "indivíduo capaz de cultura e socialmente utilizável à custa de um mínimo de perda de sua atividade" (p.1439).

8 Consta que Freud fez explicitamente preocupadas referências à situação cultural nos EUA em "El porvenir de una ilusión" (p. 2982), "El malestar en la cultura" (p. 3049) e em "El problema de la concepción del universo" (p. 3205).

9 Freud, em "El porvenir de una ilusión", refere-se à Revolução Bolchevique nos termos de "grande experiência cultural" (p. 2964), enquanto critica a pretensão de uma "piedosa América" de vir a ser God'own country (p. 2970). Entretanto, cinco anos mais tarde, em a "Lección XXXV" critica detidamente o fato de a experiência bolchevique ter se convertido em mais uma visāo do mundo.

10 Assim, também, instala-se, sob os ofícios de Anna, uma ilusão pedagógica na origem mesma da psicanálise com crianças, cuja impugnação primeira coube a M. Klein.

11 Logo mais sentencia: "o desprazer continua sendo o único meio de educação". Assim temos que a defesa contra a ameaça do inevitável desprazer organiza ou educa psiquicamente.

12 Uma intervenção incapaz de desdobrar a metáfora parental.

13 Por isso Freud declara em "Múltiple interés del psicoanálisis" que a "velha afirmação de que a nervosidade era um produto da civilização tem (apenas) uma parte de verdade" (p.1866).

14 Observe-se que nesta oportunidade em lugar de usar o tremo pedagogia, Freud vale-se de educação.

15 Cf. "La ilustración sexual del niño"; "La moral sexual cultural y la nerviosidad moderna"; "El porvenir de uma ilusión".

16 Cf. a análise exaustiva de Nelson CoeIho Jr. A Força da Realidade na Clínica Freudiana, São Paulo, 1995. No entanto, nos distanciamos no que diz respeito ao tratamento da "educação para realidade", v. pág. 103.

$17 \mathrm{Na}$ "Lección XXXV", in op. cit, Freud coloca num mesmo patamar o lugar que as obras de Marx possuíam na Rússia com a Bíblia e o Corão.

18 Freud visava dessacralizar a moral religiosa de sua época, ou seja, torná-la uma produção logicamente contingente da história dos homens, assim como o era a própria tradição científica e, portanto, não pretendia estabelecer uma fundamentação não-ilusória, num real empírico, de uma nova moral. A sua pretensão de embasar a moral numa espécie de cálculo racional ou diálogo fraterno a serviço de uma sobrevida da espécie humana com relação à "verdade psicológica" não implica necessariamente a derivação lógica de uma moral do real da ciência como se costuma pensar. Cf. de minha autoria "Psicanálise, Modernidade e Fraternidade". In M. R. Kehl (org.) Função Fraterna, Rio de Janeiro, RJ: Relume Dumara. 
$19 \mathrm{Na}$ "Lección XXI", in op. cit., Freud afirma que "o Édipo é, no fundo, uma obra imoral, pois suprime a responsabilidade do homem" (p. 2329).

20 A leitura recente de Psicanálise, Judaísmo: Ressonancias, São Paulo, SP: Escuta, 1987, de Renato Mezan, chamou nossa atenção para um comentário de Freud em uma de suas cartas ao Pastor Pfister. Esta não tinha sido notada quando da redação original deste texto. Nessa carta de 09/ 10/98 Freud refere-se a si mesmo como "um judeu absolutamente ateu". A sutil análise que Mezan realiza da carta abre a possibilidade de retomar no futuro a tese apresentada neste parágrafo.

21 Cf. "Consideraciones de actualidad sobre la guerra y la muerte". In op. cit., p. 2117.

22 Tese sustentada, em particular, por M. Cifali em Freud pédagogue?. Paris: InterEditions, 1982.

23 Cf. "La crisis de la educación". In Entre el pasado y el futuro. Barcelona: Península, 1996. 